\title{
Should I stay or should I go?
}

\author{
Karl Emanuel Busch ${ }^{1}$ and Birgitta Olofsson ${ }^{1,2, *}$ \\ ${ }^{1}$ MRC-Laboratory of Molecular Biology; Cambridge, UK; ${ }^{2}$ Department of Zoology; University of Cambridge; Cambridge, UK
}

Keywords: optimal foraging, marginal value theorem, food leaving, oxygen, carbon dioxide, metabolism

Submitted: $03 / 21 / 12$

Revised: 04/19/12

Accepted: 04/23/12

http://dx.doi.org/10.4161/worm.20464

*Correspondence to: Birgitta Olofsson;

Email: bmo21@cam.ac.uk

Commentary to: Milward K, Busch KE, Murphy RJ, de Bono M, Olofsson B. Neuronal and molecular substrates for optimal foraging in Caenorhabditis elegans. Proc Natl Acad Sci U S A 2011;

108:20672-7; PMID:22135454; http://dx.doi.org/ 10.1073/pnas.1106134109
$M$ ost animals inhabit environments in which resources are heterogeneous and distributed in patches. A fundamental question in behavioral ecology is how an animal feeding on a particular food patch, and hence depleting it, decides when it is optimal to leave the patch in search of a richer one. Optimal foraging has been extensively studied and modeled in animals not amenable to molecular and neuronal manipulation. Recently, however, we and others have begun to elucidate at a mechanistic level how food patch leaving decisions are made. ${ }^{1-3} \mathrm{We}$ found that C. elegans leaves food with increasing probability as food patches become depleted. Therefore, despite its artificial laboratory environment, its behavior conforms to the optimal foraging theory, which allowed us to genetically dissect the behavior. Here we expand our discussion on some of these findings, in particular how metabolism, oxygen and carbon dioxide regulate $C$. elegans food leaving behavior.

\section{Optimizing Foraging in Theory and Practice}

Foraging animals need to balance the benefits of remaining on their current patch of food against the prospect of identifying a better quality food patch if they leave and explore. Natural selection should therefore favor animals that are able to optimize the timing of the decision to stay or leave as their current food patch becomes depleted. The marginal value theorem (MVT) proposes that foragers should exploit patches in such a way as to maximize a net rate of energy gain, and predicts the optimal patch residence time. ${ }^{4}$ In this simple model, energy gain is a proxy for fitness and it assumes that the foragers have knowledge about the environment (i.e., the quality of other patches and traveling time between patches). MVT predicts that patch quality should affect patch leaving. Accordingly, a poor patch, yielding a lower energy gain, should be abandoned earlier (Fig. 1). Although there is a wealth of studies in behavioral ecology in support of this model, the molecular mechanisms and neural circuits basis for patch leaving is not understood in any animal. We have begun to systematically address this question using $C$. elegans. ${ }^{2}$ We measured the tendency of worms to leave a food patch in different conditions and found that in agreement with MVT, animals leave a depleted food patch with higher probability (Fig. 2). We have identified a small set of neurons and signaling molecules that either promote or repress this adaptive food leaving in response to food shortage.

Integration of ecological and physiological cues is probably key to optimizing foraging behavior. To execute an optimal foraging strategy animals most likely integrate information on three types of cues: external "gustatory" cues such as food abundance and food quality, contextual cues such as dangers, like predation and risk of desiccation, and internal cues such as current nutritional state and feeding history i.e., fat storage.

How do feeding history and metabolic state affect food leaving? Two pathways that control fat storage and metabolism in $C$. elegans are the TGF- $\beta$ and IGF signaling pathways., ${ }^{5,6}$ The TGF- $\beta$-like ligand DAF-7 coordinates energy balance 


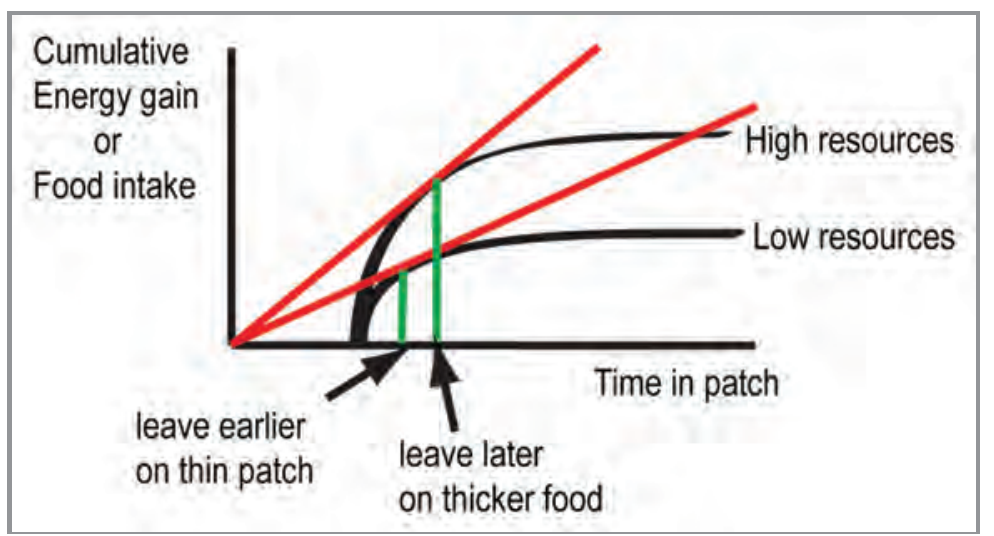

Figure 1. The marginal value theorem (MVT). The prediction by MVT is that a poor food patch should be abandoned earlier than a rich patch. The time axis starts with a travel time with no energy gain after which the forager finds a patch. The red line represents the maximum rate of energy gain for each patch. The stay-time is optimal at the tangent to the slope.

with external conditions. ${ }^{5}$ Activation of the IGF receptor DAF-2 inhibits the downstream FOXO transcription factor DAF-16 by sequestering it in the cytoplasm. ${ }^{7}$ In the absence of insulin signaling, DAF-16 enters the nucleus and upregulates genes involved in cellular stress response, microbial defense, fat and steroid hormone synthesis (and downregulates life-shortening genes). ${ }^{8}$

If the worm senses satiation, as we presume daf-16 mutants do, the feeding response may be downregulated, allowing enhanced food-leaving activity. If the worm senses food-deprivation (as the daf-2 mutants do), but can sense that it occupies a good-quality food patch, the animal's best "strategy" would be to suppress food-leaving behavior in favor of feeding, in order to utilize the nutrients on the current food patch. Ben-Arous et al. found that worms dwell on thick food and the authors suggest that dwelling is induced by a post-digestive metabolic signal. ${ }^{9}$ They reported that $d a f-2$ and daf7 mutants dwell more than wild type. We find that daf-2 animals and daf-7 animals stay strongly on food while daf-16 animals leave food with high probability. Hence the reason why both $d a f-2$ and daf7 mutants store more fat may be that these worms are constantly feeding, which is consistent with reduced quiescence in these animals. ${ }^{10}$ Wild-type food leaving is restored to daf-7 mutants by daf-7 expression in ASI and to daf-16 and age1 (PI3K) mutants by pan-neuronal expression of daf-16 and age-1, respectively. Therefore, both the TGF- $\beta$ and IGF pathways, affecting physiological state, act neuronally to control food leaving.

Oxygen and carbon dioxide sensing neurons promote food leaving. C. elegans prefers ambient $\mathrm{O}_{2}$ concentrations of $5-10 \%$ and avoids concentrations above $10 \%$. The sensory neurons URX and $A Q R$ in the head and PQR in the tail mediate this avoidance. ${ }^{11,12}$ These neurons are tonically activated by high $\mathrm{O}_{2}$ and cause animals to maintain enduring high speed, even if food is present, when ambient $\mathrm{O}_{2}$ levels are high. ${ }^{11}$ The speed of movement is one determinant of food leaving (see below). In addition, one pair of head sensory neurons called BAG responds to downshifts in $\left[\mathrm{O}_{2}\right]$ and also helps worms to locate preferred oxygen levels. ${ }^{13} \mathrm{We}$ found that the oxygen sensing neurons BAG, AQR, PQR and URX promote food leaving. In fact, when we optogenetically stimulated AQR, PQR and URX using channelrhodopsin, this induced strong food leaving. We therefore tested whether ambient oxygen levels affect food leaving. Indeed, oxygen sensitive animals, such as mutants of the neuropeptide receptor $n p r-1,{ }^{14}$ show increased food leaving in $21 \% \mathrm{O}_{2}$, in which AQR, PQR and URX are more active, compared with animals kept in $11 \% \mathrm{O}_{2}$. Thus, ambient $\mathrm{O}_{2}$ concentration is an important input that regulates foodleaving probability.
In addition to avoiding high oxygen levels, C. elegans also avoids high ambient $\mathrm{CO}_{2} \cdot{ }^{15,16} \mathrm{We}$ therefore analyzed responses to high, $3 \%, \mathrm{CO}_{2}$. High $\mathrm{CO}_{2}$ increased food leaving. BAG, together with AFD and ASE neurons, respond to increased $\mathrm{CO}_{2} \cdot{ }^{17,18}$ The food leaving response was only partially dependent on these known $\mathrm{CO}_{2}$ sensors, suggesting that also other neurons contribute to food leaving induced by $\mathrm{CO}_{2}$. The response to increased $\mathrm{CO}_{2}$ was multi-phasic. Animals showed a rapid transient increase in turning rate (data not shown) and an equally rapid but persistent increase in speed. ${ }^{15}$ In contrast, the increase in food leaving was delayed and evident only after about 10 min. Both BAG and ASE are tonically activated by $\mathrm{CO}_{2}$; perhaps this tonic component mediates avoidance, which is initially suppressed by other more transient $\mathrm{CO}_{2}$ responses. ${ }^{17}$ Thus $\mathrm{CO}_{2}$ levels also appear to regulate food leaving.

The involvement of the $\mathrm{O}_{2}$ and $\mathrm{CO}_{2}-$ sensing neurons in food leaving is further supported by rescue experiments with the cGMP-gated cation channel subunit TAX-2, which activates sensory neurons in response to numerous different sensory modalities. ${ }^{19}$ tax-2 mutant animals reduce their food leaving. The tax-2 allele (p694) we used is defective in a subset of tax-2 expressing neurons, namely AFD, BAG, ASE and the oxygen-sensing neurons $A Q R, P Q R$ and URX. Cell specific rescue in AFD, BAG, ASE or AQR/PQR/URX neurons each on their own restores food leaving to $\operatorname{tax}-2$ mutants.

Thus, high levels of $\mathrm{O}_{2}$ and $\mathrm{CO}_{2}$, as well as causing avoidance behavior by C. elegans, modify foraging by stimulating food leaving. However, these sensory signals do not simply override any food signals in an all-or-none fashion: $\mathrm{High}_{2}$ and $\mathrm{CO}_{2}$ levels increase food leaving probability, but the majority of animals still stay on food. Furthermore, worms exposed to elevated $\mathrm{CO}_{2}$ gradually increase food leaving over time. Most likely $\mathrm{O}_{2}$, $\mathrm{CO}_{2}$ and food signals are integrated in the nervous system. A clear indication for this integration is the fact that wild-type animals avoid high $\mathrm{O}_{2}$ in the absence of food, but suppress oxygen avoidance in the presence of food-in contrast to $n p r-1$ animals, which avoid $\mathrm{O}_{2}$ similarly both on 


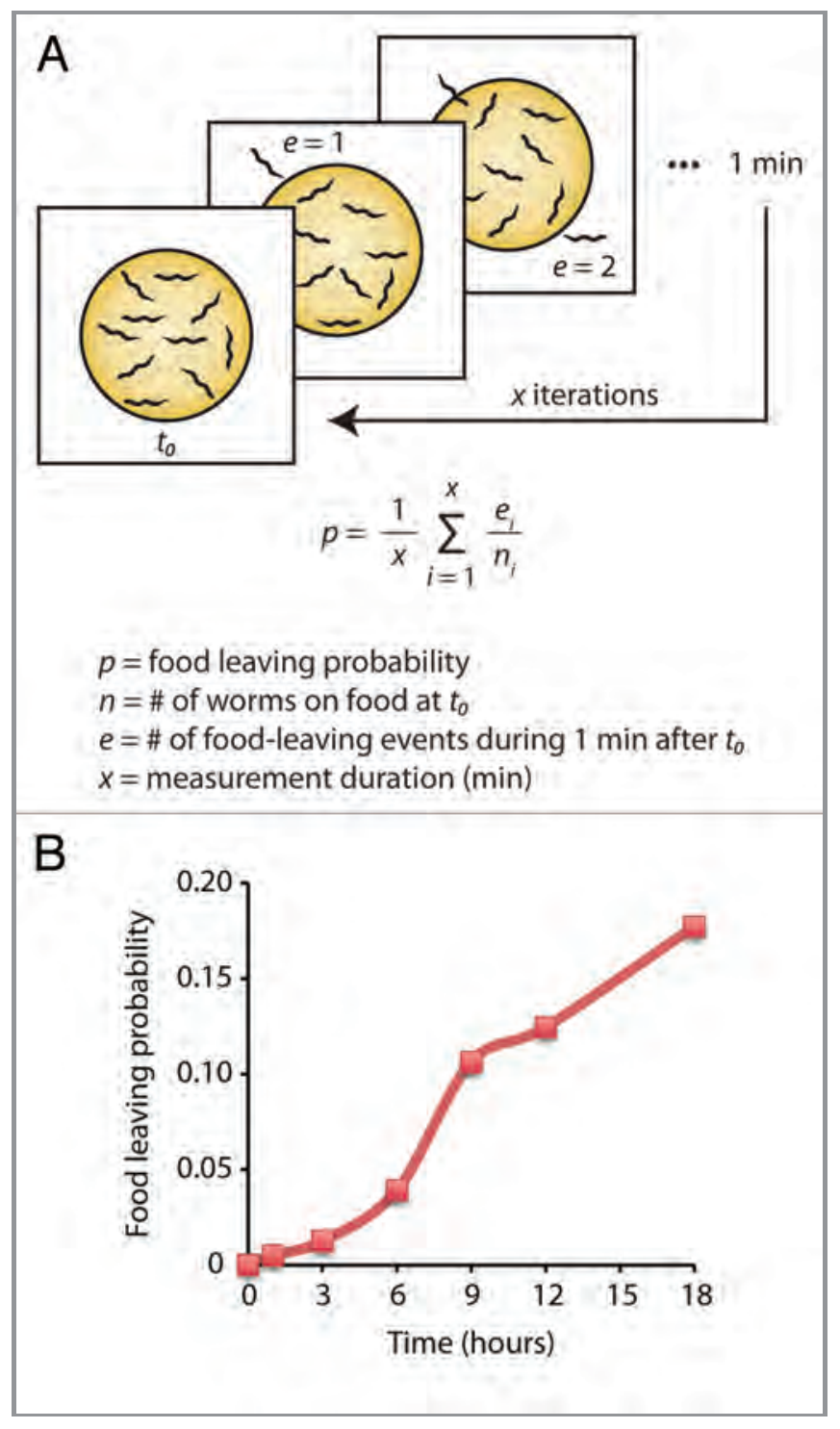

Figure 2. Food leaving in C. elegans. (A) In our assay we measured food leaving probability over time as the animals are depleting their food source. This was calculated as the number of leaving events during 1 min divided by the number of animals on food at the start of that minute. This ratio was averaged over $15 \mathrm{~min}$ intervals at each time point. (B) Wild-type animals increase food leaving as food diminishes. ${ }^{2}$

and off food. We speculate that the animal's perception of the value of the food patch is reduced in the context of high $\mathrm{O}_{2}$ and/or $\mathrm{CO}_{2}$.

Behavioral motifs underlying food leaving. Several of the mutations that affect food leaving and also levels of oxygen and carbon dioxide modify the locomotory speed of the worms. Thus, a simple explanation for food leaving could be that high locomotion translates to higher border arrival rate and hence an increased probability of a leaving event. Does high locomotory speed always correlate with high food leaving? The answer is no, although sometimes it can. Roaming (fast forward movement) is one of three behavioral states $C$. elegans display on food, the others being dwelling ${ }^{20}$ and quiescence (a state in which the animal neither feeds nor moves). ${ }^{10}$ Roaming normally accounts for $20 \%$ of the animal's behavior ${ }^{9,20}$ but roaming increases as food quality and abundance decrease. ${ }^{9,21} \mathrm{We}$ find that mutants of $n p r-1$ or of the PKG egl $-4,{ }^{22}$ two mutants that exhibit increased roaming on fresh food (high quality and abundance) also have high food leaving. In the case of $n p r-1$ animals, speed is everything. $n p r-1$ mutants have high speed and high border arrival rate and spend less time at the border. On the other hand, egl-4 mutants, which similarly move at high speed and spend less time at the border, also reduce their reversal rate at the border which additionally contributes to their increased food leaving. In contrast, che-1 mutants, ${ }^{23}$ which are defective in ASE chemosensation, exhibit wild-type roaming behavior ${ }^{9}$ and yet stay strongly on food. Also, as we mentioned previously, the initial increase in speed caused by high ambient $\mathrm{CO}_{2}$ does not correlate with high food leaving. Remarkably, tax-2 mutants behave like wild-type animals for speed, border arrival rate and border reversals, but nonetheless the proportion of animals leaving the border is reduced, which thereby accounts for the reduced probability to leave food. In summary, high speed can get the animals to the border more frequently, but it is their behavior at the border that determines whether high food leaving is a consequence.

Food leaving the context of in C. elegans ecology. C. elegans lives in microbe-rich habitats, such as those found on rotting fruit and vegetation. It is unclear what microbes form its $\operatorname{diet}^{24}$ but C. elegans is probably competing for resources with related species, such as C. briggsae and C. remanei ${ }^{25}$ and other foragers. As for other animals, there is a trade-off between feeding and environmental risks. C. elegans has natural enemies such as predacious fungi and mites. ${ }^{24}$ Abiotic features of the environment can also be dangerous and in this context we return to the importance of ambient air composition. A high $\mathrm{O}_{2}$ concentration spells danger for worms as it is often associated with exposed surfaces and accompanied by increased risk of desiccation, exposure to UV-light and rapid temperature fluctuations. Very high $\mathrm{CO}_{2}$ (above 9\%) is dangerous in itself, as it has pathophysiological effects on C. elegans, including muscle damage ${ }^{26}$ and adult wildtype $C$. elegans are repelled by increased ambient $\mathrm{CO}_{2}$ (1\% or more). ${ }^{15,16}$ Thus, the animals must balance the benefits of feeding and avoiding these dangers.

Both $\mathrm{CO}_{2}$ and $\mathrm{O}_{2}$ show substantial local variations in the habitat of free-living 


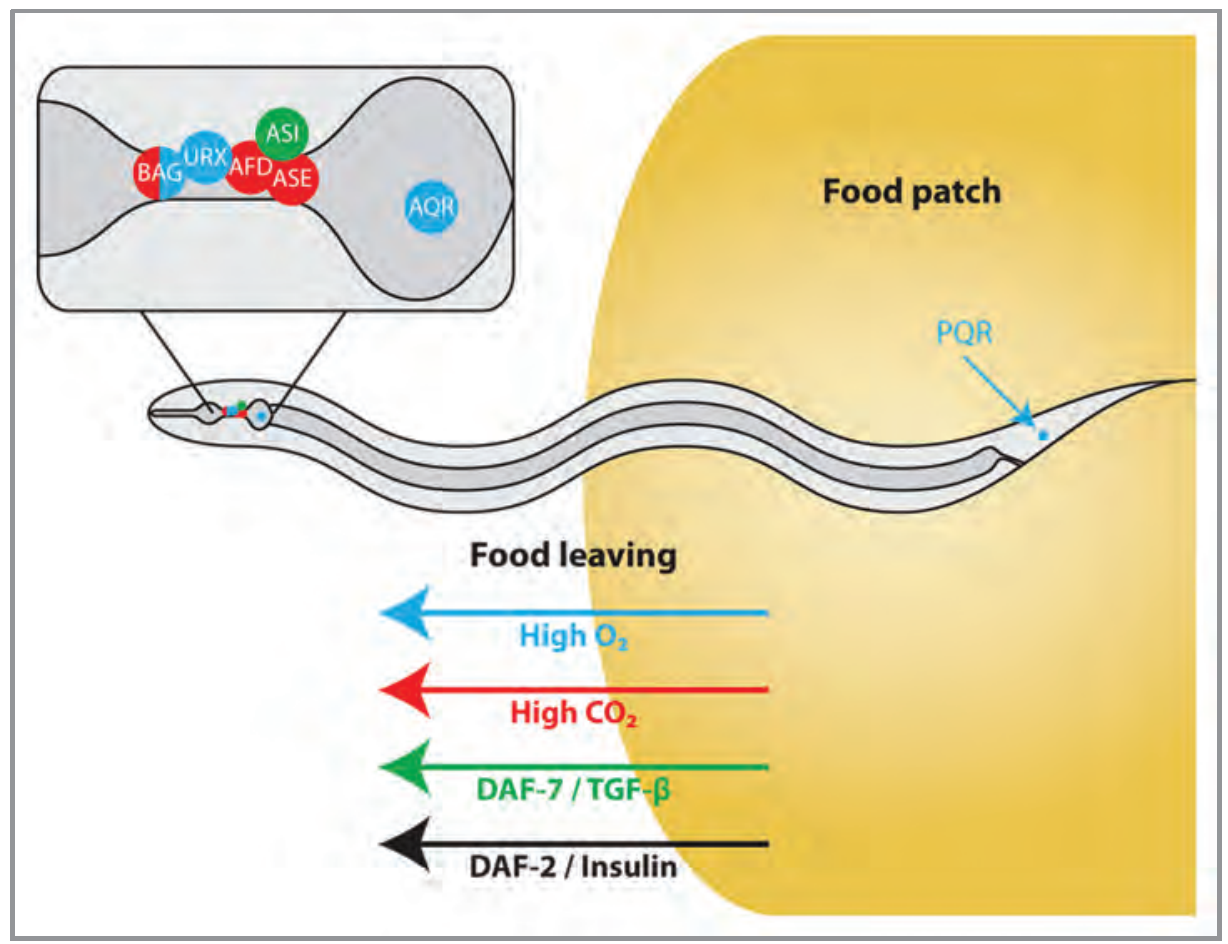

Figure 3. Schematic model of food leaving determinants in C. elegans. High $\mathrm{O}_{2}$ and $\mathrm{CO}_{2}$ levels promote food leaving, as do TGF- $\beta$ and insulin signaling.

nematodes. As a consequence, C. elegans has adapted for thriving in such environments and can tolerate extremes of gas levels. In the lab, they can survive living in $100 \% \mathrm{O}_{2}$ for many generations and can also withstand anoxia for a limited time. ${ }^{27}$ Also in the lab, levels of $\mathrm{O}_{2}$ and $\mathrm{CO}_{2}$ have little effect on reproductive fitness (above about $3 \mathrm{kPa} \mathrm{O}_{2}$ and between $0-5 \mathrm{kPa}$ $\left.\mathrm{CO}_{2}\right){ }^{28}$ Nevertheless, as discussed above, C.elegans avoids high $\mathrm{O}_{2}$ and high $\mathrm{CO}_{2}$. This suggests that, for a worm, the perceived risks associated with feeding at high $\mathrm{O}_{2}$ and/or high $\mathrm{CO}_{2}$ are related to the environment associated with those concentrations as opposed to any direct effects on fitness.

Furthermore, both gases also carry information about the presence and value of a food patch. $\mathrm{CO}_{2}$ is thought to be a kairomone, which can signal the presence of nearby organisms that may then serve as food, hosts or competitors. Hence, responses to $\mathrm{CO}_{2}$ would be expected to lead to avoidance of excessive amounts of this gas for metabolic reasons, but attraction to at least low levels for environmental reasons. Both attraction and repulsion have been observed in different nematode species. ${ }^{15,29-31} \mathrm{O}_{2}$ levels may indicate the presence of potentially beneficial organisms as bacterial colonies will deplete $\mathrm{O}_{2}$ around them and thus encourage taxis toward them. Thus, worms need to have balanced responses to these gases, which reflect the complexity of the information that they convey.

For males there is an additional and important trade-off between feeding and mate search (reproduction). In the absence of hermaphrodites, well-fed males increase their exploratory behavior including leaving food. ${ }^{32,33}$ However, this behavior is nutritional state dependent: starved males or daf-2 mutants males favor feeding above mate searching. ${ }^{33}$ This is consistent with the notion that the MVT uses too few parameters to fully predict animal behavior. Nonacs ${ }^{34}$ suggested that accurate predictions of patch exploitation need to take into account other factors such as the nutritional state of the animal, energy reserves, risk of predation and activities that can take place at the same time as foraging e.g., mate search. Only by incorporating factors such as these into a case-specific state-dependent optimality approach can actual behavior be predicted. Figure 3 illustrates how $C$. elegans balances benefits from feeding with risks, associated with environmental factors, and physiological state. The work on food leaving in C. elegans $^{1,2,35}$ provides experimental evidence for this more elaborate view on optimal foraging.

\section{Acknowledgments}

We are grateful to Howard Baylis, Mario de Bono, Kate Milward and Geoff Nelson for suggestions and critical reviewing of the manuscript. We also want to thank Geoff for making Figures 2 and 3. 


\section{References}

1. Bendesky A, Tsunozaki M, Rockman MV, Kruglyak L, Bargmann CI. Catecholamine receptor polymorphisms affect decision-making in C. elegans. Nature 2011; 472:313-8; PMID:21412235; http://dx.doi.org/10. 1038 /nature09821

2. Milward K, Busch KE, Murphy RJ, de Bono M, Olofsson B. Neuronal and molecular substrates for optimal foraging in Caenorhabditis elegans. Proc Natl Acad Sci U S A 2011; 108:20672-7; PMID:22135454; http://dx.doi.org/10.1073/pnas.1106134109

3. Hayden BY, Pearson JM, Platt ML. Neuronal basis of sequential foraging decisions in a patchy environment. Nat Neurosci 2011; 14:933-9; PMID:21642973; http://dx.doi.org/10.1038/nn.2856

4. Charnov EL. Optimal foraging, the marginal value theorem. Theor Popul Biol 1976; 9:129-36; PMID: 1273796; http://dx.doi.org/10.1016/0040-5809(76) 90040-X

5. Greer ER, Pérez CL, Van Gilst MR, Lee BH, Ashrafi K. Neural and molecular dissection of a C. elegans sensory circuit that regulates fat and feeding. Cell Metab 2008; 8:118-31; PMID:18680713; http://dx. doi.org/10.1016/j.cmet.2008.06.005

6. Kimura KD, Tissenbaum HA, Liu Y, Ruvkun G. daf-2, an insulin receptor-like gene that regulates longevity and diapause in Caenorhabditis elegans. Science 1997; 277:942-6; PMID:9252323; http://dx.doi.org/10. $1126 /$ science. 277.5328 .942

7. Lin K, Hsin H, Libina N, Kenyon C. Regulation of the Caenorhabditis elegans longevity protein DAF-16 by insulin/IGF-1 and germline signaling. Nat Genet 2001; 28:139-45; PMID:11381260; http://dx.doi.org/10. 1038/88850

8. Murphy CT, McCarroll SA, Bargmann CI, Fraser A, Kamath RS, Ahringer J, et al. Genes that act downstream of DAF-16 to influence the lifespan of Caenorhabditis elegans. Nature 2003; 424:277-83; PMID: 12845331; http://dx.doi.org/10.1038/nature01789

9. Ben Arous J, Laffont S, Chatenay D. Molecular and sensory basis of a food related two-state behavior in C. elegans. PLoS One 2009; 4:e7584; PMID:19851507; http://dx.doi.org/10.1371/journal.pone.0007584

10. You YJ, Kim J, Raizen DM, Avery L. Insulin, cGMP, and TGF-beta signals regulate food intake and quiescence in C. elegans: a model for satiety. Cel Metab 2008; 7:249-57; PMID:18316030; http://dx. doi.org/10.1016/j.cmet.2008.01.005

11. Busch KE, Laurent P, Soltesz Z, Murphy RJ, Faivre O, Hedwig B, et al. Tonic signaling from $\mathrm{O}(2)$ sensors sets neural circuit activity and behavioral state. Nat Neurosci 2012; 15:581-91; PMID:22388961; http:// dx.doi.org/10.1038/nn.3061

12. Gray JM, Karow DS, Lu H, Chang AJ, Chang JS, Ellis $\mathrm{RE}$, et al. Oxygen sensation and social feeding mediated by a C. elegans guanylate cyclase homologue. Nature 2004; 430:317-22; PMID:15220933; http://dx.doi org/10.1038/nature02714
13. Zimmer M, Gray JM, Pokala N, Chang AJ, Karow DS, Marletta MA, et al. Neurons detect increases and decreases in oxygen levels using distinct guanylate cyclases. Neuron 2009; 61:865-79; PMID:19323996; http://dx.doi.org/10.1016/j.neuron.2009.02.013

14. de Bono M, Bargmann CI. Natural variation in a neuropeptide $\mathrm{Y}$ receptor homolog modifies social behavior and food response in C. elegans. Cell 1998, 94:679-89; PMID:9741632; http://dx.doi.org/10 1016/S0092-8674(00)81609-8

15. Bretscher AJ, Busch KE, de Bono M. A carbon dioxide avoidance behavior is integrated with responses to ambient oxygen and food in Caenorhabditis elegans. Proc Natl Acad Sci U S A 2008; 105:8044-9; PMID 18524954; http://dx.doi.org/10.1073/pnas.0707607105

16. Hallem EA, Sternberg PW. Acute carbon dioxide avoidance in Caenorhabditis elegans. Proc Natl Acad Sci U S A 2008; 105:8038-43; PMID:18524955; http://dx.doi.org/10.1073/pnas.0707469105

17. Bretscher AJ, Kodama-Namba E, Busch KE, Murphy RJ, Soltesz Z, Laurent P, et al. Temperature, oxygen, and salt-sensing neurons in C. elegans are carbon dioxide sensors that control avoidance behavior. Neuron 2011; 69:1099-113; PMID:21435556; http://dx.doi.org/10.1016/j.neuron.2011.02.023

18. Hallem EA, Spencer WC, McWhirter RD, Zeller G, Henz SR, Rätsch G, et al. Receptor-type guanylate cyclase is required for carbon dioxide sensation by Caenorhabditis elegans. Proc Natl Acad Sci U S A 2011; 108:254-9; PMID:21173231; http://dx.doi.org/ $10.1073 /$ pnas. 1017354108

19. Coburn CM, Bargmann CI. A putative cyclic nucleotide-gated channel is required for sensory development and function in C. elegans. Neuron 1996; 17:695-706; PMID:8893026; http://dx.doi.org/10.1016/S08966273(00)80201-9

20. Fujiwara M, Sengupta P, McIntire SL. Regulation of body size and behavioral state of C. elegans by sensory perception and the EGL-4 cGMP-dependent protein kinase. Neuron 2002; 36:1091-102; PMID:12495624; http://dx.doi.org/10.1016/S0896-6273(02)01093-0

21. Shtonda BB, Avery L. Dietary choice behavior in Caenorhabditis elegans. J Exp Biol 2006; 209:89-102; PMID:16354781; http://dx.doi.org/10.1242/jeb.01955

22. Stansberry J, Baude EJ, Taylor MK, Chen PJ, Jin SW, Ellis RE, et al. A cGMP-dependent protein kinase is implicated in wild-type motility in C. elegans. J Neurochem 2001; 76:1177-87; PMID:11181837; http://dx.doi.org/10.1046/j.1471-4159.2001.00131.x

23. Uchida O, Nakano H, Koga M, Ohshima Y. The C. elegans che-1 gene encodes a zinc finger transcription factor required for specification of the ASE chemosensory neurons. Development 2003; 130:1215-24; PMID: 12588839; http://dx.doi.org/10.1242/dev.00341
24. Félix MA, Braendle C. The natural history of Caenorhabditis elegans. Curr Biol 2010; 20:R965-9; PMID:21093785; http://dx.doi.org/10.1016/j.cub. 2010.09.050

25. Kiontke K, Sudhaus W. Ecology of Caenorhabditis species. WormBook 2006; 1-14; PMID:18050464

26. Sharabi K, Hurwitz A, Simon AJ, Beitel GJ, Morimoto RI, Rechavi G, et al. Elevated CO2 levels affect development, motility, and fertility and extend life span in Caenorhabditis elegans. Proc Natl Acad Sci U S A 2009; 106:4024-9; PMID:19237558; http://dx.doi. org/10.1073/pnas.0900309106

27. Van Voorhies WA, Ward S. Broad oxygen tolerance in the nematode Caenorhabditis elegans. J Exp Biol 2000; 203:2467-78; PMID:10903161

28. Freyth K, Janowitz T, Nunes F, Voss M, Heinick A Bertaux J, et al. Reproductive fitness and dietary choice behavior of the genetic model organism Caenorhabditis elegans under semi-natural conditions. Mol Cells 2010; 30:347-53; PMID:20821059; http://dx.doi.org/10. 1007/s10059-010-0125-9

29. Sciacca J, Forbes WM, Ashton FT, Lombardini E, Gamble HR, Schad GA. Response to carbon dioxide by the infective larvae of three species of parasitic nematodes. Parasitol Int 2002; 51:53-62; PMID: 11880227; http://dx.doi.org/10.1016/S1383-5769 (01)00105-2

30. Plot JC. Migration of plant-parasitic nematodes towards plant roots. Revue de Nematologie 1980; 305-18.

31. Pline M, Dusenbery DB. Responses of plant-parasitic nematode Meloidogyne incognita to carbon dioxide determined by video camera-computer tracking. J Chem Ecol 1987; 873-88; http://dx.doi.org/10.1007/ BF01020167

32. Barrios A, Nurrish S, Emmons SW. Sensory regulation of C. elegans male mate-searching behavior. Curr Biol 2008; 18:1865-71; PMID:19062284; http://dx.doi. org/10.1016/j.cub.2008.10.050

33. Lipton J, Kleemann G, Ghosh R, Lints R, Emmons SW. Mate searching in Caenorhabditis elegans: a genetic model for sex drive in a simple invertebrate. J Neurosci 2004; 24:7427-34; PMID:15329389; http:// dx.doi.org/10.1523/JNEUROSCI.1746-04.2004

34. Nonacs P. State dependent behavior and the Marginal Value Theorem. Behav Ecol 2001; 12:71-83; http://dx. doi.org/10.1093/oxfordjournals.beheco.a000381

35. Gloria-Soria A, Azevedo RB. npr-1 Regulates foraging and dispersal strategies in Caenorhabditis elegans. Cur Biol 2008; 18:1694-9; PMID:18993077; http://dx. doi.org/10.1016/j.cub.2008.09.043 